\title{
РОЛЬ ЁМКОСТИ РЫНКА СРЕДСТВ ПРОТИВОВОЗДУШНОЙ ОБОРОНЫ ПРИ ОБОСНОВАНИИ БЕЗУБЫТОЧНОСТИ ПРОИЗВОДСТВА
}

\section{ROLE OF AIR DEFENSE MARKET CAPACITY IN JUSTIFICATION OF PRODUCTION RELIABILITY}

\section{A. Kryukov \\ O. Bezverkhy}

Summary. The general characteristics of the world air defense market and the key concepts of market capacity are considered. A study of the competitive positions of the Russian concern A0 Concern VKO AlmazAntey on the domestic and world arms market was carried out. The role of the market capacity in justifying the break-even production of domestic air defense systems based on the materials of the Concern VKO Almaz-Antey JSC is disclosed. The business idea, strategy, tactics and forecast of the demand for weapons with new properties of Russian production have been substantiated.

Keywords: market capacity, production break-even, arms and military equipment market, air defense means, military products.
Крюков Алексей Анатольевич

Исследователь, АО «Кониерн воздушно-космической обороны «Алмаз-Антей»

kryukov.a_almaz@bk.ru

Безверхий Олег Анатольевич

Заместитель генерального директора,

AO «Машиностроительное конструкторское бюро «Факел» имени академика П.Д. Грушина»

bezverkhy@mail.ru

Аннотация. Рассмотрена общая характеристика мирового рынка средств ПВО и ключевые понятия емкости рынка. Проведено исследование конкурентных позиций российского концерна АО «Концерн ВКО «Алмаз-Антей» на отечественном и мировом рынке вооружений. Раскрыта роль емкости рынка при обосновании безубыточности производства отечественных средств ПВ0 на материалах АО «Концерн ВКО «Алмаз-Антей». Обоснована бизнес - идея, стратегия, тактика и прогноз востребованности средства вооружения с новыми свойствами российского производства.

Ключевые слова: емкость рынка, безубыточность производства, рынок вооружений и военной техники, средства противовоздушной обороны, продукция военного назначения.

Емкость мирового рынка вооружений и военной техники оценивается конъюнктурой торговли, тенденциями изменения ее динамики и структуры. В сложившихся условиях высокой изменчивости мировых финансовых рынков, а также значительного уровня неопределенности и рисков в реализации инвестиционных проектов государственных корпораций в сфере разработки систем ПВО усиливается необходимость в оценке емкости рынка и обосновании безубыточности производства.

\section{Метолы}

Исследование емкости рынка проводили различные отечественные исследователи, в частности, Пехальский М.И., Денисова Т.С., Каратаева О.Г., Медведева О.Е., Мясникова А.В., Попова А.В., Силина Е., Воронин В.П. и другие. Ряд научных трудов посвящен перспективам российских производителей и выпускаемых образцов ПВО на мировом и отечественном рынке вооружений. Например, это исследования авторов: Башкиров Е.Р., Иваха Г.Ю., Юмашева Е.В., Бердников П.М., Черепанов Н.В., Мальцев Н.В. 
Однако, аргументация вывода на рынок новых образцов ПВО невозможна без детального обоснования безубыточности производства современных образцов средств ПВО, которая в свою очередь основывается на исследовании перспектив продвижения военной продукции на российском и мировом рынке на основе емкости рынка.

\section{Цель исслеАования}

Рассмотреть понятие емкости рынка и обосновать безубыточность производства средств ПВО и продвижения на уникальных монополизированных рынках.

\section{Результаты исслеАования}

Одним из основных показателей, отражающих перспективы роста спроса на продукцию военного назначения на мировом рынке, является емкость рынка. Специфика оружейного рынка заключается в том, что отдельные средства ПВО достаточно высоко востребованы, одновременно с этим другие образцы вооружений и военной техники (далее - ВиВТ) теряют свои рыночные позиции в условиях развития инновационных и цифровых технологий, усовершенствования технических параметров вооружения и оснащения вооруженных сил противников. Проектирование средств ПВО начинается с разработки технико-экономического обоснования, формирования производственной программы, сметы затрат и калькуляции себестоимости, оценки потребности в инвестициях и привлечении источников финансирования [1].

Среди основных факторов, оказывающих влияние на емкость рынка средств ПВО, являются: сложившаяся геополитическая ситуация в мире, особенности и интенсивность протекания вооруженных конфликтов, обеспеченность вооруженных сил государств средствами обороны, их техническое состояние, уровень государственного финансирования, цены на оборонную продукцию и технические параметры, которые определяют спрос и перспективы сбыта. Следовательно, емкость рынка средств ПВО - это потенциально возможный объем сбыта, достижимый на рынках вооружения при достаточном финансировании заказчиков. Емкость рынка вооружений зависит от рыночных факторов, например, курс валют, политика конкурентов, политическая обстановка [2].

Потенциальная емкость рынка традиционно определяется путем прогнозирования исходя из максимального объема продаж, фактическая же - путем оценки объемов реализации продукции военного назначения конкретными заказчиками на основе предварительно заключенных договоров на поставку. Определение ем- кости рынка средств ПВО позволяет идентифицировать долю рынка не только страны, но и каждого производителя на мировом рынке вооружений и дальнейшие перспективы ее изменения. На основе данных показателей планируются объемы сбыта проектируемой ПВН на действующих и новых рынках, обосновываются критерии оценки результатов работы сбытовых и сервисных служб [3]. Без емкости рынка компания рискует недополученной прибылью из-за неполного удовлетворения возрастающего спроса на средства ПВО с техническими характеристиками, превышающими мировые аналоги, и с конкурентной ценой. При этом спрос на такую продукцию может расти более высокими темпами при сложившейся рыночной конъюнктуре [3]. После оценки потенциальной емкости рынка прогнозируется спрос и темпы роста рынка, на которых базируется темп роста масштабов производства и потенциал инновационного продукта в сфере производства ПВН.

Инвестиционный проект принимается к реализации при приемлемом сроке окупаемости капиталовложений, рентабельности инвестиций, точке безубыточности и запасе финансовой прочности.

Экономическое обоснование реализуемых инвестиционных проектов по разработке и выпуску средств ПВО с заданными техническими параметрами основывается на прогнозе динамики доходов и затрат, которые на протяжении периода реализации проекта или срока эксплуатации изделия корректируются на коэффициент дисконтирования, определенный исходя из дисконтной ставки, обеспечивающей инвестору необходимую норму прибыли (дохода) [9].

Рассмотрим емкость мирового рынка вооружений. Для мирового экспорта ВиВТ до 2008 года были характерны стабильные годовые темпы роста. Объем экспорта в 2008 году составил 46,985 млрд. долл. Глобальный финансовый кризис 2009 года привел к сокращению мирового объема экспортных поставок вооружений до рекордного за последние 10 лет значения - 44,655 млрд. долл. Восстановление военного экспорта уже в 2010 году достигло объемов в 53,327 млрд. долл., годовой темп роста при этом составил 19,42\%. В 2011 году данный показатель достиг значения в 59,132 млрд. долл. (годовой темп роста - 10,58\%) (таблица 1).

В 2012-2013 гг. наблюдалось сокращение объемов торговли оружием на глобальном рынке, вызванное рецессией мировой экономики. Всемирный экспорт ВиВТ в 2012 году составил 58,160 млрд. долл. с отрицательным годовым темпом прироста в 1,64\%. В 2013 году сокращение мирового объема экспорта ВиВТ составило 55, 590 млрд. долл., годовой темп прироста составил $-4,42 \%[4]$. 
Таблица 1. Общемировые военные расходы, военный экспорт/импорт и ВВП в 2011-2018 гг. [4]

\begin{tabular}{|l|l|l|l|l|l|l|l|l|l|}
\hline Годы & $\mathbf{2 0 1 1}$ & $\mathbf{2 0 1 2}$ & $\mathbf{2 0 1 3}$ & $\mathbf{2 0 1 4}$ & $\mathbf{2 0 1 5}$ & $\mathbf{2 0 1 6}$ & $\mathbf{2 0 1 7}$ & $\mathbf{2 0 1 8}$ & $\mathbf{2 0 1 1 -}$ \\
\hline $\begin{array}{l}\text { Мировые военные } \\
\text { расходы, млрд. долл. }\end{array}$ & 1635,2 & 1626,3 & 1626,8 & 1630,2 & 1563,3 & 1575,5 & 1598,9 & 1678,3 & 12934,5 \\
\hline $\begin{array}{l}\text { Темп прироста } \\
\text { к предыдущему } \\
\text { году,\% }\end{array}$ & $-0,54$ & 0,03 & 0,21 & $-4,10$ & 0,78 & 1,48 & 4,97 \\
\hline $\begin{array}{l}\text { Военный экспорт/ } \\
\text { импорт, млрд. долл. }\end{array}$ & 59,1 & 58,2 & 55,6 & 67,6 & 74,3 & 81,2 & 86,6 & 84,8 & 567,3 \\
\hline $\begin{array}{l}\text { Темп прироста } \\
\text { к предыдущему } \\
\text { году,\% }\end{array}$ & $-1,64$ & $-4,42$ & $+21,57$ & $+9,98$ & $+9,24$ & $+6,61$ & $-2,08$ \\
\hline $\begin{array}{l}\text { Соотношение } \\
\text { экспорта/ импорта } \\
\text { к военным } \\
\text { расходам,\% }\end{array}$ & 3,62 & 3,58 & 3,42 & 4,15 & 4,75 & 5,15 & 5,41 & 5,05 & 4,39 \\
\hline $\begin{array}{l}\text { Мировой ВВП, трлн. } \\
\text { долл. }\end{array}$ & 72,8 & 74,2 & 76,3 & 78,4 & 74,2 & 75,2 & 79,6 & 84,2 & 614,9 \\
\hline $\begin{array}{l}\text { Темп прироста ВВП } \\
\text { к предыдущему } \\
\text { году,\% }\end{array}$ & 1,90 & 2,84 & 2,70 & $-5,31$ & 1,40 & 5,82 & 5,74 \\
\hline
\end{tabular}

Таблица 2. Структура поставок по категориям на период 2019-2022 гг.

(млрд. долл. в текущих ценах) [4]

\begin{tabular}{|l|l|l|l|l|l|l|l|}
\hline ВиВТ & $\mathbf{2 0 1 1 - 2 0 1 4}$ & $\mathbf{2 0 1 5 - 2 0 1 8}$ & $\mathbf{2 0 1 9}$ & $\mathbf{2 0 2 0}$ & $\mathbf{2 0 2 1}$ & $\mathbf{2 0 2 2}$ & $\mathbf{2 0 1 9 - 2 0 2 2}$ \\
\hline Средства ПВО & 21,72 & 37,80 & 10,85 & 6,71 & 10,71 & 13,17 & 41,45 \\
\hline Структура,\% & 9,03 & 11,56 & 11,21 & 6,96 & 9,89 & 11,21 & 9,89 \\
\hline Зенитные ракетные системы & 18,54 & 35,02 & 10,32 & 5,71 & 9,47 & 12,00 & 37,50 \\
\hline Зенитные артиллерийские установки & 0,73 & 1,69 & 0,38 & 0,51 & 0,64 & 0,60 & 2,13 \\
\hline ПЗРК & 2,45 & 1,09 & 0,15 & 0,49 & 0,60 & 0,58 & 1,82 \\
\hline БЛА & 3,90 & 6,48 & 3,24 & 4,64 & 2,44 & 3,35 & 13,66 \\
\hline Структура,\% & 1,62 & 1,98 & 3,34 & 4,81 & 2,25 & 2,85 & 3,26 \\
\hline БЛА класса МАLЕ и НALЕ & 2,04 & 4,71 & 2,69 & 4,40 & 2,25 & 3,22 & 12,56 \\
\hline Тактические БЛА & 1,55 & 1,47 & 0,22 & 0,14 & 0,10 & 0,10 & 0,55 \\
\hline Мини и микро БЛА & 0,32 & 0,31 & 0,33 & 0,10 & 0,09 & 0,03 & 0,55 \\
\hline
\end{tabular}

Объемы мировой торговли ВиВТ имел место в 2014 году значительно возросли до 67,584 млрд. долл. (+21,57\%). В 2015 году объем торговли оружием достиг 74,334 млрд. долл., темп прироста составил 9,98\%. В 2016 году - 81,200 млрд. долл. (темп прироста 9,24\%), в 2017 году - 86,572 млрд. долл. (темп прироста 6,61\%). В 2018 году динамика торговли вооружением была отрицательна $(84,769$ млрд. долл., темп прироста составил $-2,08 \%)$.

Причиной рост объемов экспорта ВиВТ в 20142017 гг. является начало поставок США вооружений и военной техники в страны Ближнего Востока (прежде всего, Саудовской Аравии) [4].
В 2011-2018 гг. США лидировали по объему заказов на разработку и поставку вооружений - 367,636 млрд. долл., что составляет 45,7\% в структуре всемирного портфеля контрактов. В 2017 году США заключили максимальный объем контрактов на сумму 72,311 млрд. долл. (69,75\% от суммы всех контрактов на разработку и поставку вооружений в 2017 году). На втором месте находится РФ, сумма заказов составила 93,940 млрд. долл. (11,7\%) в 2011-2018 гг. Другие ключевые западноевропейские поставщики вооружений, а также Израиль и Китай значительно уступают России [4].

Рассмотрим оценку потенциальной емкости рынка на период 2019-2022 гг. в разрезе категорий ВиВТ, 


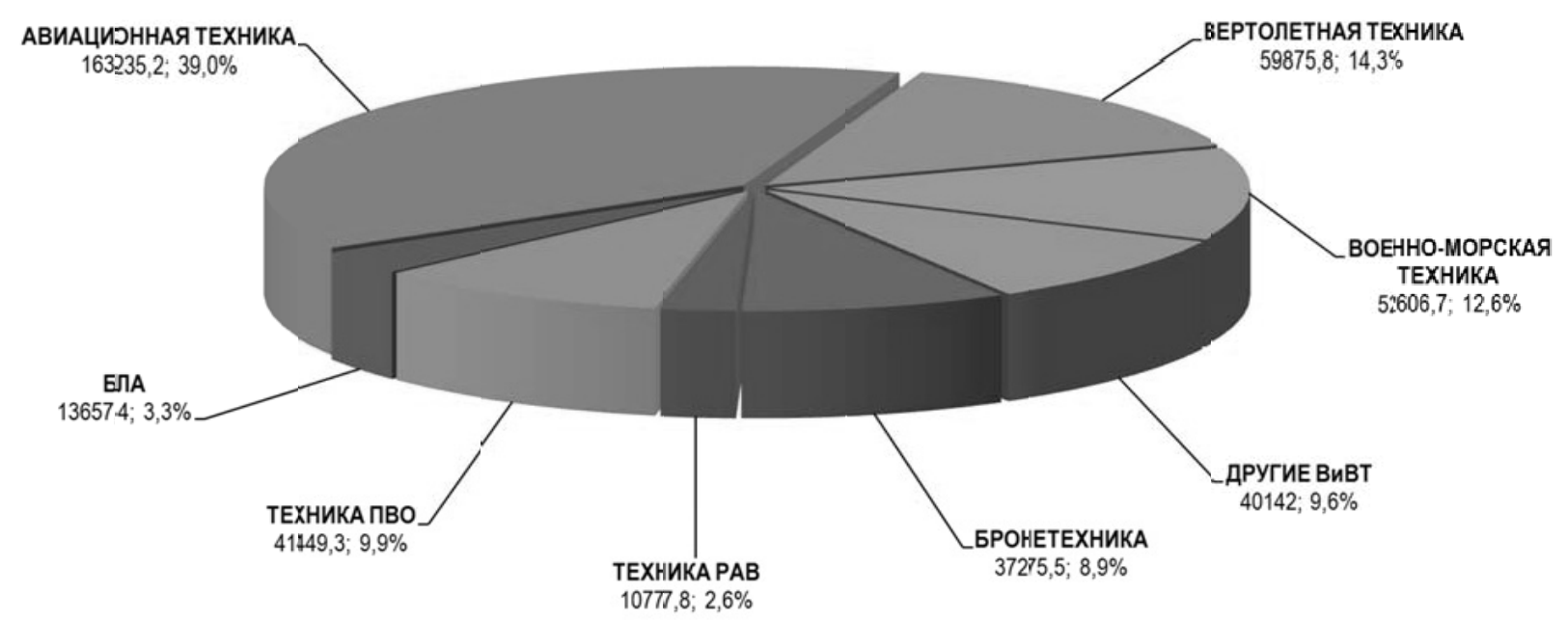

Рис. 1. Структура мировых поставок ВиВТ по идентифицированным контрактам в 2019-2022 гг. (млн. долл. в текущих ценах) [4]

на основе заключенных контрактов на октябрь 2019 г. Объемы экспорта по категориям ВиВТ показаны в периодах 4 года, использованных для наглядности оценки.

В ближнесрочной перспективе в структуре мирового военного экспорта наблюдается фактическое сохранение объемов продаж средств ПВО, она сохранят за собой 4 место (долевой объем сократится с 10,49\% до 9,89\% - снижение на 0,6\%), однако ожидается существенное увеличение долевого объема продаж по категориям беспилотных летательных аппаратов. Существующий уровень развития средств дистанционного управления средствами вооружения кардинально меняет требования к полезной нагрузке и тактике применения летательного аппарата: из обязательных систем исключены системы жизнеобеспечения пилота, снижаются требования по защищенности летательного аппарата, становится принципиально возможной потеря техники в ходе боестолкновения. Также снижаются накладные расходы на ее содержание и эксплуатацию. Данный факт является знаковым в структуре применяемых сил и средств, и в дальнейшем, скорее всего, изменит структуру экспорта средств противовоздушной обороны России.

С 2011 по 2018 гг. ежегодный объем вновь заключаемых контрактов превышал объем фактического экспорта. Это доказывает стабильное развитие мирового рынка вооружений.

В 2011 году темп роста мирового объема заключенных контрактов достиг 142\% к фактическому объему экспорта вооружений, в 2012 году - 153\%, в 2013 году - 126,2\%, в 2014 году - 169,3\%, в 2015 году-
144,4\%, в 2016 году - 124,3\%, в 2017 году - 137,5\% и в 2018 году - 140,4\% [4].

Общий мировой пакет экспортных заказов на поставку ВиВТ в 2011-2018гг. составил 803,897 млрд. долл., существенно превышая фактический экспорт (567,342 млрд. долл.). «Переходящий» портфель мировых заказов на поставку ПВН на перспективу по данным 2011-2018 гг. составляет 236,5 млрд. долл.

Пакет заказов на 2020-2022 гг. в части средств ПВО проходит стадию окончательного формирования и в ближайшее время стоит ожидать его пополнения.

Таким образом, мы наблюдаем устойчивый спрос в ближнесрочной, а скорее всего и в долгосрочной перспективе, на средства противовоздушной обороны при значительном увеличении количества, роли и порядке боевого применения беспилотных летательных аппаратов.

Рост спроса на глобальном рынке на зенитные ракетные системы (далее - ЗРС) ПВО российского производства в долгосрочном периоде объясняется их высокими тактико-техническими параметрами и преимуществами российских ЗРС над западными аналогами, прежде всего, американскими. Превосходство российских ЗРС над аналогами производства США подтверждено зарубежными экспертами, которые считают, что технический уровень средств ПВО России позволяет фактически исключить возможность «выживания» авиации ВВС США при военном конфликте. Это является исключительно важным стратегическим преимуществом на внешних рынках вооружения [6]. 
Среди комплексов малой (и отчасти средней) дальности разработаны новые модели зУР с использованием инновационных головок с активным радиолокационным самонаведением, укомплектованными иногда авиационными ракетами с инфракрасным самонаведением. Примеры таких комплексов - американский SLAMRAAM и американо-норвежский NASAMS, которые применяют ракеты AIM-120 AMRAAM, а также европейский MICA VL, израильский Spyder. Данные 3PK пользуются спросом на рынке вооружений и в ближайшее время займут большую его часть [7].

Основными зарубежными поставщиками средств ПВО/НПРО на мировой рынок вооружения являются компании из США (Lockheed Martin, Raytheon Company), стран Западной Европы (Thales - Франция, Saab Швеция, Kongsberg - Норвегия, MBDA - консорциум компаний Италии, Великобритании, Франции, Германии) и Израиля (IAI и Rafael) [6]. Правительства данных государств традиционно рассматривают экспорт ВВСТ, в том числе систем ПВО, как стратегическое направление обеспечения национальных интересов, требующее приоритетных мер государственной поддержки для сохранения и усиления позиций оборонных предприятий [8].

На мировом оружейном рынке Россия предлагает высокоэффективные ЗРК малой дальности с командным наведением, среди которых: ЗРК серии «Тор», зенитные ракетно-пушечные комплексы семейств «Тунгуска» и «Панцирь-С1» [8].

В последние годы Россия наращивает долю мирового рынка ЗРС/ЗРК за счет высокой конкурентоспособности отечественных средств ПВО и разработанных российскими конструкторами систем всех возможных классов. В некоторых сегментах российские разработки уникальны на мировом рынке, в частности, «Тор» «Панцирь-С1», С-350 [9].

AO «Концерн ВКО «Алмаз-Антей» является холдингом радиоэлектронной промышленности полного цикла в России. Концерн разрабатывает, производит модернизирует, обслуживает, поддерживает работоспособность, ремонтирует и утилизирует ЗРС и ЗРК, их элементов, РЛК, РЛО, систем автоматизированного управления оружием и иной продукции различного назначения. Средства ПВО/НПРО производимые Концерном - это сложные, наукоемкие и высокотехнологичные образцы ВВСТ, которые поставляются в ВС РФ и на экспорт.

В России Концерн лидирует в ОПК в сфере проектирования систем ПВО/ПРО. Концерн разрабатывает и поставляет продукцию по заказам Минобороны в рамках
ГОЗ и Государственной программы вооружения. Общая доля Концерна в разработке, серийном производстве и эксплуатации средств ПВО/НПРО в рамках ОПК России составляет 75-80\% [10]. Концерн занимает прочную позицию на мировом рынке в своей нише. По оценкам экспертов, доля ПВН, выпускаемых Концерном, достигает 65-75\% в структуре экспорта средств ПВО/НПРО. Экспортные заказы составляют значительную долю в структуре общего портфеля заказов Концерна. В Концерн входя большинство разработчиков и производителей систем и средств ВКО в России. В сегменте ЗРС большой и средней дальности на российском рынке Концерн является монополистом. Концерн наращивает объемы выпуска средств ПВО, улучшает результаты НИОКР, которые позволяют разрабатывать современные ПВН с высокими техническими параметрами. Все это позволяет сделать вывод, что сложившееся на сегодняшний день устойчивое положение Концерна сохранится в ближайшем будущем [11].

АО «Концерн ВКО «Алмаз-Антей» планирует разработку и реализацию проекта выпуска новых средств ПВО в сегменте ЗРК на российском и мировом рынке. Проектируемый комплекс должен иметь собственные средства слежения за воздушной обстановкой, сопровождения целей и наведения оружия. Одновременно с этим необходимо использовать системы связи и управления, позволяющие отдельному комплексу передавать собранную информацию другим потребителям, а также получать целеуказание из сторонних источников. Отдельные комплексы и целые батареи должны формировать единую информационную сеть, «накрывающую» крупные районы. Такая возможность в некоторой мере упростит организацию ПВО, а также повысит боеспособность отдельных соединений за счет возможности своевременного оповещения о возможных угрозах. Как показывает имеющийся опыт эксплуатации современных 3РК, важнейшей особенностью их бортового оборудования является автоматизация различных процессов.

Необходимо провести оценку соответствия научных и производственно-технологических возможностей Концерна ВКО «Алмаз-Антей» поставленной задаче по разработке перспективных средств противовоздушной обороны по противодействию БЛА.

Для оценки влияния проекта по созданию средства ПВО с новыми свойствами на организационно-производственную структуру АО «Концерн ВКО «Алмаз-Антей» и используемые технологии рассмотрим ключевые характеристики компонент.

В настоящее время системы ПВО малого радиуса действия используют ракетное вооружение (семейство 
«Тор») или комбинированный комплекс с ракетами и пушками («Панцирь-С1»). Такой подход к вооружению зенитных комплексов целесообразно сохранить. Наличие в периметре Концерна Машиностроительного конструкторского бюро «Факел» ОКБ «Новатор», Долгопрудненского научно-производственного предприятия, ведущих разработчиков ракетной техники в России и мире с численностью работников более 10000 человек позволяет позитивно оценивать перспективы создания новейших ударных средств поражению [12].

Анализ существующих средств радиолокационного обнаружения показывает, что основные приложение научно-практического потенциала Концерна будет необходимо произвести в данном сегменте. Все эксплуатируемые системы зенитно-ракетного и зенитно-артиллерийского вооружения предназначены для поражения воздушных целей малых, средних и крупных размеров. Однако, после разработки современных малоразмерных БЛА, показатели разведывательных и огневых возможностей борьбы с ними у эксплуатируемых сегодня средств ПВО существенно снижаются [7].

В качестве примера перспективного образца вооружения можно привести комплекс обнаружения и противодействия БЛА «РЛК-МЦ-А» производства НПО «Лианозовский электромеханический завод», который способен обнаруживать объекты на дальности до 20 км. В качестве основного средства обнаружения используется обзорная трехкоординатная РЛС X-диапазона, в которой впервые применена полностью адаптивная система СДЦ. Благодаря этому РЛС комплекса эффективно обнаруживает и сопровождает малоскоростные, малоразмерные цели. В качестве дополнительного источника информации в комплексе «РЛК-МЦ» используется поворотная оптико-электронная система с телевизионном каналом, которая работает по целеуказанию от РЛС комплекса. Еще одним источником дополнительной информации являются встроенные в комплекс средства радиоэлектронного пеленгования и воздействия, которые обеспечивают обнаружение, пеленгацию и воздействие на источники радиоизлучения БЛА в широком диапазоне частот.

Как пример компактных радиолокационных систем можно рассмотреть РЛС «Фара-ВР» и «Соболятник-О» разработки и ПАО «НПО «Стрела» [14]. Аналогичные разработки разной степени реализации инициативно ведутся ФНПЦ «ННИИРТ», НПО «Алмаз», ВНИИРТ, НПО НИИИП-НЗиК, входящими в состав Концерна, являющимися ведущими предприятия России по созданию радиолокационной техники.

Концерн и его дочерние общества, прежде всего НПО «Алмаз», являются разработчиками большинства эксплуатируемых автоматизированных систем управления, средствами ПВО, эксплуатируемых Министерством обороны России, таким как «Байкал», «Эльбрус», «Вертикаль», «Фундамент», «Москва», «Универсал», «Пирамида», АСУ Войск ПВО и ВКО [6].

Рассмотрим требования по мобильности современных систем ПВО. В настоящий момент ведется разработка Министерством обороны Российской Федерации унифицированных бронированных платформ «Курганец-25», «Бумеранг» и «Армата». Все они в теории могут стать основой для перспективных ЗРК. Применение подобных шасси позволит унифицировать зенитные комплексы с другой бронетехникой войск, благодаря чему упростится совместная эксплуатация разных образцов, а также будут исключены возможные проблемы с работой в одних боевых порядках.

Анализируя рынок аналогов вооружения, рассмотрим комплекс обнаружения и противодействия БЛА «РЛК-МЦ-А» ориентировочной стоимостью 150 млн. Данный комплекс уступает по механизмам поражения [13].

В реестре госконтрактов заключен 24 декабря 2012 года с ОАО «Ижевский электромеханический завод «Купол» договор на поставку Минобороны РФ военной техники, входящей в состав войскового ЗРК «ТорM1-2У» [15].

Еще один аналог - зенитно-ракетный пушечный комплекс «Панцирь С1» (по классификации НАТО SA-22 Greyhound), разработанный тульским ГУП «Конструкторское бюро приборостроения», который позволяет вести борьбу с воздушными, легкобронированными наземными целями, защищать военные и промышленные объекты. В комплексе комплекса - автоматические пушки и управляемые ракеты [16]. «Панцирь-С1» пользуется спросом на зарубежном рынке. Российские ПЗРК закупили Алжир, Ирак, Сирия, ОАЭ, Оман, Иордания и Бразилия [17].

Наиболее перспективно создание средства защиты от воздушного нападения роев БЛА с минимальным ЭПР в облике: отдельно стоящая машина, с малоразмерным классом целей (только очень маленькие, не очень быстрые ЛА), с высокой степенью автоматизации, с новой зенитной управляемой ракетой сверх малой дальности. Обоснована целесообразность реализации проекта созданию новейшего образца вооружения на производственных мощностях АО «Концерн ВКО «Алмаз-Антей» с описанными выше свойствами. Разработка новых средств ПВО с заданными техническими характеристиками требует обоснования безубыточности, которая в свою очередь основывается на данных по прогнозу объемов продаж, то есть потенциальной емкости рынка. 


\section{ВывоАы и преАложения}

Рост спроса на глобальном рынке на ЗРС российского производства в долгосрочном периоде объясняется их высокими тактико-техническими параметрами и преимуществами российских ЗРС над западными аналогами, прежде всего, американскими. Анализ емкости рынка средств ПВО показал, что в 2011-2018 г. сумма мировых поставок средств ПВО составила 59,515 млрд. долл., или 10,49\% в структуре поставок всех категорий вооружений. Касаемо потенциальной емкости рынка, в ближнесрочной перспективе в структуре мирового военного экспорта наблюдается фактическое сохранение объемов продаж средств ПВО. Пакет заказов на 2019-2022 гг. в части средств ПВО в настоящий момент сформирован более чем на 50\%, следует ожидать заключения дополнительных контрактов. Устойчивый спрос в ближнесрочной и долгосрочной перспективе на средства ПВО обу- словлен значительным увеличением количества, роли и направлений боевого применения беспилотных летательных аппаратов.

Основные тенденции в развитии новейших комплексов ПВО заключаются в появлении возможности работы по малоразмерным целям, сохранении многоканальности, возможность поражения высокоскоростных целей, в том числе баллистических.

На мировом рынке Россия предлагает высокоэффективные комплексы малой дальности с командным наведением. Среди них - ЗРК серии «Тор», уникальные зенитные ракетно-пушечные комплексы семейств «Тунгуска» и «Панцирь-С1». Анализ фактической и потенциальной емкости рынка средств радиолокационного обнаружения показал, что реализация научно-практического потенциала АО «Концерн ВКО «Алмаз-Антей» в данном сегменте имеет перспективы.

\section{ЛИТЕРАТУРА}

1. Пехальский М.И., Денисова Т.С., Каратаева 0.Г. Методы определения расчета емкости рынка. Международный научный журнал. 2018. № 5-6. С. 69-78.

2. Медведева 0.Е., Мясникова А.В., Попова А.В. Емкость целевого рынка, как часть отраслевого экономического анализа. Инновационное развитие экономики. 2019. № 3 (51). С. 139-144.

3. Силина Е., Воронин В.П. Определение емкости рынка. Материалы студенческой научной конференции за 2018 год. В 2 ч. 2018. С. 199.

4. Глава 1. Мировые расходы на оборону в 2011-2018 гг. Сайт ЦАМTO. URL: https://armstrade.org/pages/main/magazines/yearly/report/1/index.shtml

5. Статистика и анализ мировой торговли оружием. Ежегодник ЦАМТО — 2019. URL: https://armstrade.org/files/yearly_2019_1_1.pdf

6. Безель Я.В. Развитие и совершенствование автоматизированных систем управления воздушно-космической обороны и испытательной базы межвидового испытательного полигона Минобороны России // Вестник Концерна ПВ0 «Алмаз-Антей». № 2. 2015. С. 13-15.

7. Ростопчин В.В. Ударные беспилотные летательные аппараты и противовоздушная оборона — проблемы и перспективы противостояния // Беспилотная авиация 2019. URL: https://www.researchgate.net/publication/331772628_Udarnye_bespilotnye_letatelnye_apparaty_i_protivovozdusnaa_ oborona_problemy_i_perspektivy_protivostoania

8. Башкиров Е.Р., Иваха Г.Ю., Юмашева Е.В. Россия на мировом рынке вооружения: современное состояние и перспективы развития // Международный студенческий научный вестник. 2018. № 4-5. С. 758-762.

9. Бердников П.М. Россия на международном рынке вооружений // Современное состояние и перспективы развития национальной финансово-кредитной системы Сборник материалов III Международной научной конференции студентов специалитета, бакалавриата и магистратуры. Под редакцией С.П. Федосовой. 2019. С. 334-336.

10. Зайцев Н.А., Платов А.В., Потапов В.А. Радиолокационные станции разведки наземных движущихся целей. Современный уровень и основные направления развития // Вестник Концерна ПВО «Алмаз-Антей». № 1. 2014. С. 41-44.

11. Аминов С. Итоги деятельности Концерна ПВО «Алмаз-Антей» в 2019 году // Экспорт вооружений. № 6(147). С. 2-5.

12. Черепанов Н.В., Мальцев Н.В. Конкурентоспособность предприятий оборонно-промышленного комплекса России на международном рынке вооружений // Конкурентоспособность субъектов хозяйствования в условиях новых вызовов внешней среды: проблемы и пути их решения Сборник материалов Международной научно-практической конференции. Под общей редакцией Н.В. Мальцева. 2019. С. 394-398.

13. Зайцев Н.А., Сидоров В.В., Адякин Ю.Н. Радиолокационные комплексы на беспилотных летательных аппаратах — перспективное направление построения разведывательных систем // Вестник Концерна ПВ0 «Алмаз-Антей». № 2(12). 2014. С. 35-38.

14. Новиков Я.В. Функционирование и развитие ОПК в условиях современных вызовов // Вестник Концерна ПВ0 «Алмаз-Антей». № 3. 2015. С. 5-10.

15. Новый контракт на 3PK «Тор-M1-2У». URL: https://sdelanounas.ru/blogs/28083/

16. Непробиваемый «Панцирь»: почему российский комплекс ПВО считается одним из самых эффективных в мире. URL: https://tvoi54.ru/posts/1698udarnaja-mosch-pancirja-pochemu-rossiiskomu-zrpk-pancir-s1-net-ravnyh-v-mire-the-national-inter.html.

17. Зенитный ракетно-пушечный комплекс «Панцирь-C1». URL: https://militaryarms.ru/voennaya-texnika/artilleriya/pancir-s1/

18. Бондаренко Н.В., Матюшина Е.Ю. Проблемы повышения конкурентоспособности России на мировом рынке вооружений и военной техники // Проблемы устойчивого развития экономики в условиях геополитических вызовов современности Материалы Международной заочной научно-практической конференции. 2017. С. 23-26. 
19. Дальченко Е.А., Лемешко 0.Е. Мировой рынок вооружений. экспорт и импорт вооружения России // Лучшая научная статья 2019. Сборник статей XXVIII Международного научно-исследовательского конкурса. 2019. С. 29-32.

20. Зверев А.А. Высокотехнологичный экспорт России на мировом рынке вооружений // Валютное регулирование. Валютный контроль. 2019. № 1-2. C. 26-34.

21. Суханова Ю.Н. Россия на мировом рынке вооружений и военной техники в современных условиях // Актуальные проблемы и перспективы развития экономики: российский и зарубежный опыт. 2019. № 21. С. 79-83.

22. Уваркина М., Молодова А.С. Военно-промышленный комплекс России и его место на международном рынке вооружений и военной техники // Школа юных инноваторов. Сборник научных статей Итоговой конференции проектов. 2018. С. 394-396.

23. Ягьяев Р.А. Проблемы и перспективы участия России на мировом рынке вооружений и военной техники // Инновационная наука. 2018 . № 1. С. 43-47. 24. Приблизительная стоимость оружия, боеприпасов. URL: https://monster.livejournal.com/42346.html

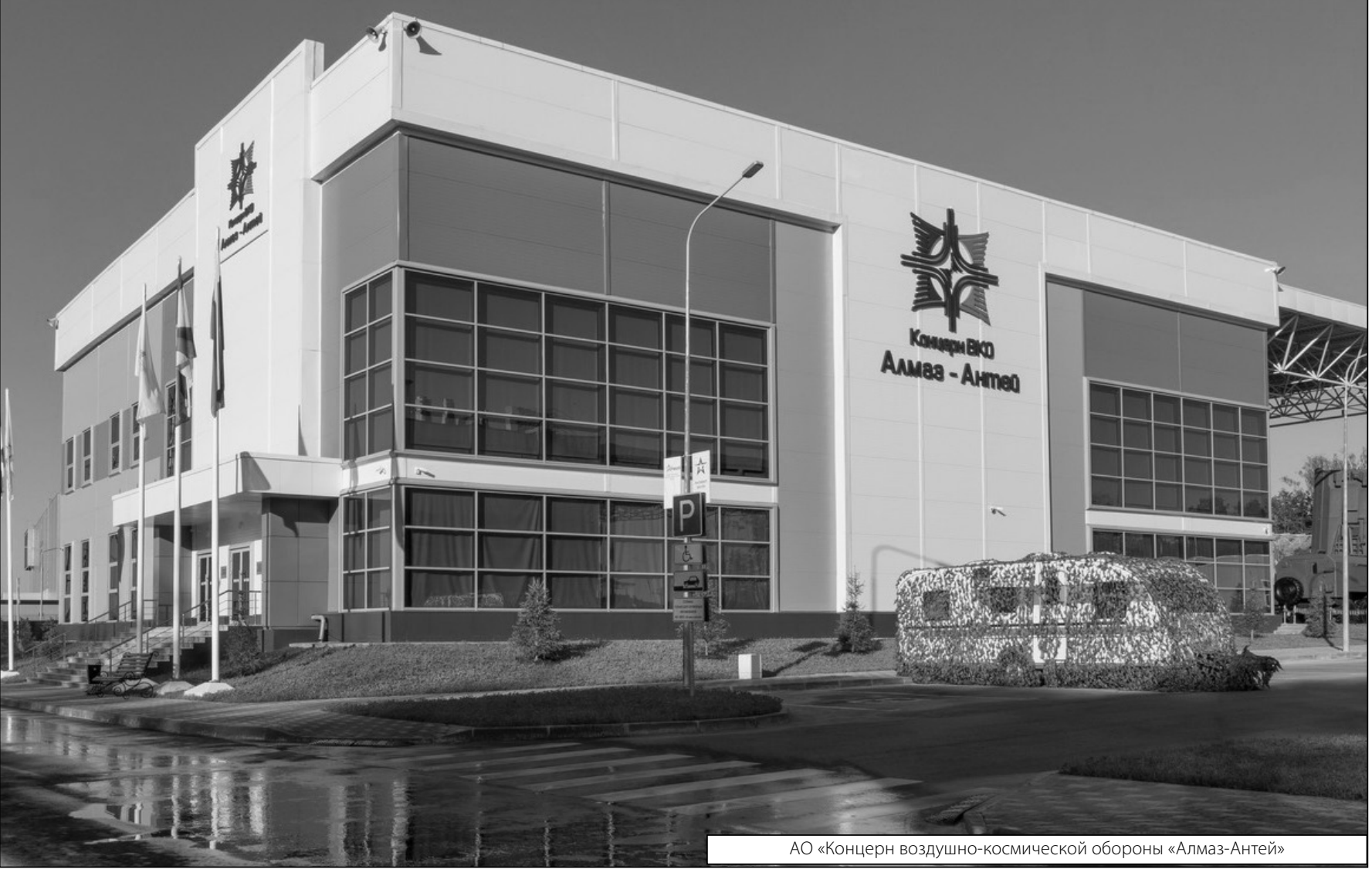

